\title{
Pengelolaan Pemangkasan Tanaman Teh (Camellia sinensis (L.) O. Kuntze) di Unit Perkebunan Tambi, Wonosobo, Jawa Tengah
}

\section{Management of Tea (Camellia sinensis (L.) O Kuntze) Pruning at Plantation Unit of Tambi Wonosobo, Central Java}

\author{
Aldi Radifan dan Supijatno* \\ Departemen Agronomi dan Hortikultura, Fakultas Pertanian, Institut Pertanian Bogor \\ (Bogor Agricultural University), Jl. Meranti, Kampus IPB Darmaga, Bogor 16680, Indonesia \\ Telp.\&Faks.62-251-8629353 e-mail agronipb@indo.net.id \\ "Penulis untuk korespondensi : supijatno@yahoo.co.id
}

Disetujui 16 Januari 2017/ Published Online 24 Januari 2017

\begin{abstract}
The activities was conducted in order to improve knowledge, field experience, and to study tea management aspect which is related to tea pruning. In general internship was to improve students' skills in studying and understanding the real work processes and provide managerial experience in the management of plantation crops. The specific purpose of this internship is to obtain information on the management of pruning Tambi tea plantation unit. Internship activities was conducted at Tambi Plantation, Wonosobo, Central Java from February until June 2015. Direct method was conducted by doing and observing. Indirect method was conducted by collecting management report. Results showed that pruning criteria that plant heigt is $<120 \mathrm{~cm}$ and percentage of dormant buds is > $70 \%$; type of pruning; prunning implementation time is divided into two semesters; rotation prunning implemented $4-5$ years and pruning the number of personnel has met the standards of the Indonesian Plantation Research Institute (PPTK). Prunning machine is more effective than manual prunning assessed from time management.
\end{abstract}

Keywords : Plantation Unit of Tambi, prunning, prunning machine, tea

\section{ABSTRAK}

Kegiatan dilaksanakan untuk memperluas pengetahuan, pengalaman teknis dan manajerial tanaman teh serta mempelajari aspek pemangkasan. Secara umum kegiatan magang ini bertujuan untuk meningkatkan keterampilan mahasiswa dalam mempelajari dan memahami proses kerja secara nyata dan memberikan pengalaman manajerial pada pengelolaan tanaman perkebunan. Adapun tujuan khusus dari magang ini adalah untuk memperoleh informasi mengenai pengelolaan pemangkasan tanaman teh di Unit Perkebunan Tambi. Kegiatan magang dilaksanakan di Perkebunan Tambi, Wonosobo, Jawa Tengah pada bulan Februari sampai Juni 2015. Metode langsung dilakukan secara aktif mengikuti dan mengamati kegiatan teknis. Metode tidak langsung dilakukan dengan mengumpulkan laporan manajemen. Hasil magang menunjukan bahwa kriteria pangkasan yaitu tinggi tanaman $<120 \mathrm{~cm}$ dan persentase pucuk burung > 70\%; jenis pangkasan, waktu pelaksanaan pemangkasan dibagi menjadi dua semester; gilir pangkas yang dilaksanakan 4 - 5 tahun dan jumlah tenaga pemangkas telah memenuhi standar Lembaga Riset Perkebunan Indonesia (PPTK). Pemangkasan mesin lebih efektif daripada pemangkasan manual dinilai dari manajemen waktu.

Kata kunci : pemangkasan, pemangkasan mesin, unit perkebunan tambi, teh 


\section{PENDAHULUAN}

Teh merupakan salah satu komoditi yang berperan penting dalam strategi perekonomian Indonesia. Tahun 2010 teh merupakan salah satu komoditas perkebunan yang menjadi penghasil devisa bagi Indonesia sebesar US\$ 178 juta (Rukmana 2015). Teh sebagai bahan minuman penyegar dan menyehatkan merupakan salah satu komoditas unggulan perkebunan di Indonesia. Selain itu perkebunan teh merupakan salah satu sumber lapangan pekerjaan, sumber pendapatan asli daerah (PAD) dan difungsikan untuk menjaga kelestarian lingkungan (Syah 2006).

Pada tahun 2012, areal perkebunan teh Indonesia terus mengalami penurunan pada lahan perkebunan teh di Indonesia. Ditjenbun (2013) menyebutkan bahwa produksi teh pada perkebunan teh pada tahun 2013 mengalami penurunan menjadi 145460 ton dengan luas areal 122035 ha dibandingkan tahun 2012 sebesar 168 053 serta dengan luas areal sebesar $152217 \mathrm{ha}$. Tahun 2013 data produktivitas teh sebesar 1465 $\mathrm{kg} \mathrm{ha}^{-1}$ sedikit menurun dibandingkan tahun 2012 sebesar $1472 \mathrm{~kg} \mathrm{ha}^{-1}$. Penurunan produksi dapat disebabkan oleh penurunan luas lahan dan produktivitas pucuk yang rendah.

Kegiatan budidaya yang berperan penting untuk meningkatkan produktivitas dan menghambat pertumbuhan kayu adalah pemangkasan sedangkan untuk mengatasi sifat berkala pertumbuhan pucuk dapat diatasi dengan pemetikan. Pemangkasan dapat mempertahankan tanaman pada fase vegetatif, merangasang pertumbuhan tunas muda sehingga menghasilkan pucuk lebih banyak, membentuk bidang petik, mengganti dan mempermudah percabangan tanaman (Suwarto dan Octavianty 2010).

Pemangkasan pada tanaman teh dilakukan pada tanaman menghasilkan dan tanaman belum menghasilkan. Pemangkasan pada tanaman menghasilkan bertujuan untuk mengusahakan pertumbuhan tanaman teh agar tetap pada fase vegetatif, membuat bidang petik tetap rendah, membentuk bidang petik seluas mungkin, merangsang pertumbuhan tunas-tunas baru dan mengatur fluktuasi produksi harian agar stabil. Pemangkasan pada tanaman belum menghasilkan bertujuan untuk membentuk perdu dengan kerangka percabangan yang ideal dan bidang petik yang luas (Pusat Penelitian Teh dan Kina 2006).

Secara umum kegiatan magang bertujuan untuk memperoleh pengalaman kerja, keterampilan dan pengetahuan. Selain itu, kegiatan magang juga bertujuan untuk menerapkan secara langsung ilmu yang sudah didapatkan selama menjalani perkuliahan dengan membandingkan pelaksanaan pemangkasan tanaman teh di lapang. Secara khusus kegiatan magang bertujuan untuk mempelajari pengelolaan pemangkasan melalui analisis-analisis aspek pemangkasan yang dilakukan selama dalam kegiatan magang.

\section{METODE PENELITIAN}

Kegiatan penelitian dilaksanakan di Unit Perkebunan Tambi, Wonosobo, Jawa Tengah selama empat bulan dari 16 Februari hingga 16 Juni 2015. Metode pelaksanaan dilakukan dengan kegiatan teknis di lapangan dan aspek manajerial pada berbagai tingkatan status yang masing masing tingkatan dilaksanakan selama empat minggu pada setiap tingkatan. Data primer diperoleh dengan bekerja secara aktif dan pengamatan di lapangan. Aspek penelitian secara khusus yang dipelajari di perkebunan adalah pengelolaan pemangkasan dengan rincian kegiatan diantaranya yaitu mengikuti pelaksanaan pemangkasan, mengamati dan mempelajari teknis pelaksanaan, mengamati kondisi tanaman, mempelajari aspek manajemen pemangkasan dan pelaksanaan pengawasan pemangkasan.

Pengumpulan data sekunder diperoleh dari laporan manajemen, arsip di kantor induk dan kantor pabrik serta melalui studi pustaka. Pengumpulan data primer terdiri atas tinggi bidang petik, diameter bidang petik, persentase pucuk burung, jenis pangkasan, tinggi pangkasan, diameter bidang pangkas, luas areal pangkasan per hari, kebutuhan tenaga pemangkas per hari, alat pangkas, waktu pelaksanaan pemangkas dan pertumbuhan pucuk. Pengamatan tanaman dilakukan pada tanaman dengan umur pangkas I IV tahun setelah pangkas. Data sekunder yang diamati adalah produksi pucuk.

Analisis data dan informasi dilakukan dengan menggunakan hasil rata - rata dari pengamatan yang telah dilakukan, hasil wawancara dan studi pustaka. Data yang diperoleh dianalisis secara kuantitatif dan kualitatif nilai rata - rata dan diuraikan secara deskriptif dengan membandingkan standar perusahaan dengan studi pustaka dan melakukan analisis untuk mengetahui hubungan produksi dan faktor yang mempengaruhinya menggunakan uji $t$ - student pada taraf 5\%. Nilai berbeda nyata apabila $\mathrm{t}$ hitung $>\mathrm{t}$ tabel dan tidak berbeda nyata apabila $\mathrm{t}$ hitung $<\mathrm{t}$ tabel, $\mathrm{t}$ tabel diperoleh dari nilai sebaran $\mathrm{t}$ pada taraf $5 \%$ dan $\mathrm{db}(\mathrm{n} 1+\mathrm{n} 2-2)$ (Walpole 1992). 


\section{HASIL DAN PEMBAHASAN}

\section{Keadaan Umum}

Unit Perkebunan (UP) Tambi terletak di Desa Tambi Kecamatan Kejajar Kabupaten Wonosobo dengan ketinggian tempat $1200-2$ $100 \mathrm{~m}$ dpl. Blok Pemandangan terletak di Desa Sigedang, Kecamatan Kejajar, Kabupaten Wonosobo dan merupakan blok tertinggi di UP Tambi yaitu sekitar $1700-2100 \mathrm{~m}$ dpl. Blok Taman terletak di Desa Tambi, Kecamatan Kejajar, Kabupaten Wonosobo dengan ketinggian tempat mencapai $1300-1500 \mathrm{~m}$ dpl. Blok Panama terletak di Desa Tlogo, Kecamatan Garung, Kabupaten Wonosobo dengan ketinggian tempat antara 1250 - $1500 \mathrm{~m}$ dpl. Blok Tanah Hijau terletak di Desa Jengkol, Kecamatan Garung, Kabupaten Wonosobo dengan ketinggian tempat $1000-1250 \mathrm{~m}$ dpl.

Curah hujan selama sepuluh tahun terakhir (2004 - 2014) berkisar antara 2351 - 3 $661 \mathrm{~mm}$ dan hari hujan berkisar antara $113-196$ hari. Rata - rata bulan kering 2.9 dan rata - rata bulan basah 7.8, sedangkan tipe iklim berdasarkan curah hujan menurut Schmidth - Ferguson adalah tipe B. Suhu di Unit Perkebunan Tambi berkisar antara $17{ }^{\circ} \mathrm{C}-23{ }^{\circ} \mathrm{C}$ dengan kelembaban udara berkisar pada angka $80-95 \%$. Jenis tanah di Unit Perkebunan Tambi adalah Andosol dengan $\mathrm{pH} 4.5$ - 5.0. Tekstur tanah Unit Perkebunan Tambi adalah Geluh dengan kedalaman efektif solum yaitu $40-70 \mathrm{~cm}$. Keadaan drainase di lahan Unit Perkebunan Tambi adalah sedang sampai dengan cepat. Topografi lahan pada umumnya memiliki tingkat kemiringan $0-45 \%$.
Berdasarkan Rencana Kerja dan Anggaran Pendapatan (RKAP) tahun 2015, luas lahan UP Tambi adalah 273.17 ha. Luas areal TM yaitu sebesar 221.89 ha dan areal TBM/replanting yaitu sebesar 25.28 ha, sedangkan sisanya seluas 26 ha digunakan untuk pembibitan, kebun perbanyakan, pabrik, agrowisata serta sarana dan prasarana penunjang. Unit Perkebunan Tambi dibagi menjadi empat blok yaitu Blok Pemandangan seluas 68.32 ha, Blok Taman seluas 53.23 ha, Blok Panama seluas 60.96 ha dan Blok Tanah Hijau dengan luas 39.38 ha, kemudian setiap luasan blok dibagi menjadi 15 nomer atau leger.

Tanaman teh yang dibudidayakan di UP Tambi terdiri dari klon Gambung 3, Gambung 4, Gambung 7, TRI 2024, TRI 2025, Tambi Merah (klon lokal), Malabar Pasir Sarongge (MPS), Kiara 8, Cin 143 dan Seedling (Hibrid dan Assam). Jarak tanam untuk jenis klon yaitu 120 $\mathrm{cm} \times 75 \mathrm{~cm}$, sedangkan untuk seedling yaitu 130 $\mathrm{cm} \times 90 \mathrm{~cm}$ atau tidak beraturan. Populasi per hektar untuk jenis klon sekitar 11000 pohon dan 7000 - 10000 pohon per hektar untuk jenis seedling.

\section{Tinggi Bidang Petik}

Tinggi bidang petik dapat menjadi salah satu indikator pelaksanaan pemangkasan sebab sangat berpengaruh terhadap keefektifan dan kapasitas pemetik dalam mencapai hasil panen. Seiring dengan pertumbuhan umur pangkas maka tanaman teh akan semakin tinggi. Pengamatan tinggi bidang petik dapat dilihat pada Gambar 1.

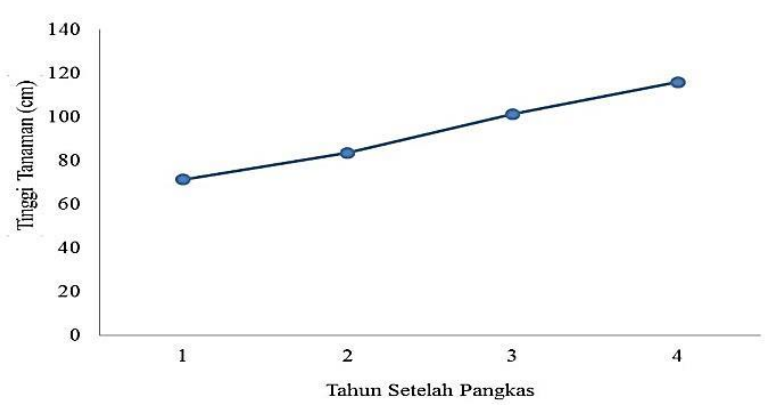

Gambar 1. Tinggi Bidang Petik Tanaman terhadap Umur Pangkas di UP Tambi 2015

Tinggi tersebut sudah sesuai dengan literatur yang ada, menurut Johan dan Dalimoenthe (2009) tinggi bidang petik yang ideal adalah sekitar $80-110 \mathrm{~cm}$. PPTK (2006) menyebutkan bahwa ketinggian tanaman yang memiliki tinggi lebih dari $120 \mathrm{~cm}$ sudah tidak ergonomis bagi pemetik, hal ini akan mempengaruhi efektifitas dan kapasitas pemetik tersebut. Oleh karena itu saat tanaman berumur 4 tahun setelah pangkas tanaman telah siap untuk dipangkas.

\section{Diameter Bidang Petik}

Diameter bidang petik menandakan tanaman teh semakin produktif, sebab diameter 
yang lebar akan menjadikan tanaman tersebut semakin rapat. Semakin rapat frame atau diameter maka semakin sedikit serangan hama dan penyakit terhadap tanaman teh tersebut. Pertumbuhan diameter akan bertambah seiring bertambahnya umur per tahun pangkas tanaman teh sama hal nya seperti yang ada pada UP Tambi. Pengamatan diameter bidang petik dapat dilihat pada Tabel 1.

Tabel 1. Diameter Bidang Petik Tanaman terhadap Umur Pangkas di UP Tambi 2015

\begin{tabular}{lcccc}
\hline \multirow{2}{*}{ Blok } & \multicolumn{5}{c}{ Diameter bidang petik/tahun setelah } \\
& \multicolumn{5}{c}{ pangkas } \\
\cline { 2 - 5 } & I & II & III & IV \\
\cline { 2 - 5 } & 77.9 & 86.9 & 102.1 & 124.1 \\
\hline Pemandangan & 78.1 & 93.8 & 103 & 122.2 \\
Taman & 73.3 & 97.8 & 113.6 & 137.9 \\
Panama & 82.7 & 96.5 & 115.1 & 129.8 \\
Tanah Hijau & $78 \mathrm{a}$ & $93.7 \mathrm{a}$ & $108.4 \mathrm{a}$ & $128.5 \mathrm{a}$ \\
\hline Rata-rata & \multicolumn{5}{c}{}
\end{tabular}

Hasil pengamatan yang telah dilakukan di UP Tambi tahun 2015 memiliki diameter lebih lebar daripada hasil pengamatan yang dilakukan di UP Tambi tahun 2013 yaitu sebesar $77.27 \mathrm{~cm}-$ $87.34 \mathrm{~cm}$ (Rosiantim 2013). Hasil pengamatan menunjukan berbeda nyata pada tiap tahun pangkas setelah di uji-t dengan membandingkan diameter tanaman umur empat tahun setelah pangkas. Diameter tanaman yang lebar menandai kesehatan tanaman, semakin lebar frame maka semakin sehat tanaman tersebut. Diameter yang lebar akan berpeluang lebih besar dalam menghasilkan pucuk yang lebih banyak pula, namun apabila terlalu lebar akan mengganggu kegiatan pemetikan dan menutup jalan kontrol.

\section{Persentase Pucuk Burung}

Salah satu indikator yang juga menandakan bahwa tanaman teh telah siap untuk dipangkas adalah pucuk burung. Tanaman teh akan menghasilkan pucuk burung lebih banyak dibandingkan pucuk peko dengan semakin meningkatnya umur daun pemeliharaan (Sukasman 1990). Pucuk burung adalah pucuk yang memiliki tunas dalam keadaan dorman. Gambar 2 menunjukan pengamatan antara pucuk peko dengan pucuk burung.

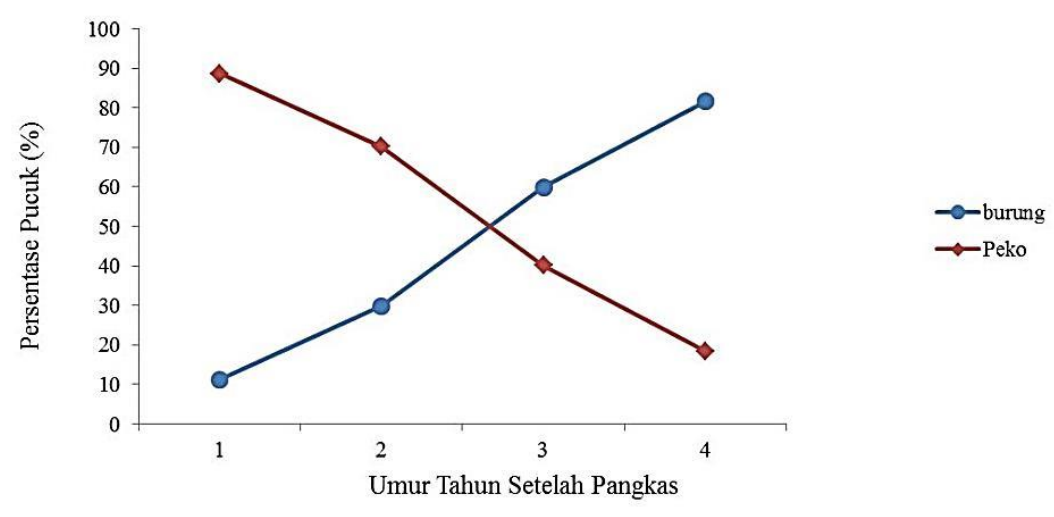

Gambar 2. Persentase pucuk burung dan pucuk peko terhadap umur tanaman di UP Tambi 2015

Kriteria pemangkasan adalah persentase pucuk burung pada tanaman $>70 \%$. Sebab tingginya jumlah pucuk burung mengindikasikan tingginya zat pati hasil fotosintesis yang terakumulasi dari akar teh, makin aktif pertumbuhan pucuk maka semakin banyak zat pati yang digunakan, sehingga zat pati semakin berkurang dalam persediaan tanaman (PPTK 2006).

\section{Jenis Pangkasan}

Berdasarkan pengamatan yang telah dilakukan, jenis pangkasan yang dilaksanakan di Unit Perkebunan Tambi beragam diantaranya pangkasan bersih, setengah bersih dan jambul. Pangkasan bersih dilakukan pada saat musim penghujan karena penyinaran dan suhu tidak terlalu tinggi sehingga tunas dapat tumbuh dengan baik, kemudian pangkasan jambul dilakukan karena pangkasan yang dilakukan telah mendekati musim kemarau karena batang yang disisakan berfungsi untuk menghindari kematian tanaman dan melindungi tunas yang akan tumbuh dari sinar matahari. Namun dalam pelaksanaannya pangkasan yang dilakukan oleh para pekerja sebagian besar adalah pangkasan setengah bersih, hal ini dikarenakan pangkasan tersebut mudah dilakukan pada tanaman yang memiliki batang batang yang besar dan lebar. Kemudian 
kebanyakan tenaga pemangkas terburu - buru dalam melaksanakan pangkasan. Tenaga pemangkas lebih mengutamakan kuantitas daripada kualitas karena tenaga yang dibayar adalah tenaga borongan. Sehingga semakin cepat pekerjaan yang diselesaikan maka lebih cepat bayaran yang akan mereka dapat.

\section{Tinggi dan Diameter Pangkasan}

Ketinggian pangkasan merupakan suatu ukuran untuk memenuhi kriteria yang ditetapkan oleh perusahaan. Ketinggian pangkasan diukur dari permukaan tanah hingga permukaan bidang pangkas. Tinggi pangkasan untuk kebun produktif (TM) biasanya berkisar antara $40-70 \mathrm{~cm}$. Menurut Johan dan Dalimoenthe (2009) tinggi pangkasan yang lebih rendah dari $40 \mathrm{~cm}$ akan menyebabkan percabangan yang terbentuk terlalu rendah sehingga menyulitkan pemetik, sedangkan tinggi pangkasan yang lebih dari $70 \mathrm{~cm}$ akan menyulitkan apabila tanaman akan dipangkas kembali. UP Tambi menetapkan sistem pangkasan tetap pada ketinggian antara $45-60 \mathrm{~cm}$.penulis melaksanakan pengamatan pada empat blok yang ada dan menetapkan standar pangkasan $55 \mathrm{~cm}$ (Tabel 2).

Tabel 2. Rata - rata tinggi pangkasan dan diameter bidang pangkas UP Tambi 2015

\begin{tabular}{cccccc}
\hline Blok & $\begin{array}{c}\text { No. } \\
\text { kebun }\end{array}$ & $\begin{array}{c}\varnothing \\
\text { pangkas }\end{array}$ & $\mathrm{n}$ & \multicolumn{2}{c}{ Tinggi pangkasan } \\
\cline { 5 - 6 } & pengamatan standar \\
\hline Taman & 4 & 72.66 & 10 & 53.76 & 55 \\
Tanah & & & & & \\
Hijau & 15 & 75.34 & 10 & 51.97 & 55 \\
$\begin{array}{c}\text { Panama } \\
8\end{array}$ & 75.90 & 10 & 55.13 & 55 \\
$\begin{array}{c}\text { Pemandang } \\
\text { an }\end{array}$ & 3 & 64.01 & 10 & 53.37 & 55 \\
\hline Rata-rata & & 71.97 & & 53.56 & 55 \\
\hline
\end{tabular}

Dari data hasil pengamatan penulis dapat dilihat ketinggian pangkasan pada setiap blok tidak selalu sama, namun sudah hampir memenuhi standar yang telah ditetapkan oleh perusahaan. Faktor dari adanya perbedaan antara standar dengan pengamatan antara lain, kondisi kesehatan tanaman, kondisi lahan, keterampilan tenaga kerja dan penggunaan alat ukur yang tidak baku. Tanaman yang sehat akan dipangkas sesuai dengan standar yang ditetapkan, namun lain halnya dengan tanaman yang sakit untuk mengantisipasi agar tanaman tidak mati maka pangkasan yang dilakukan akan lebih tinggi dari standar yang ditetapkan. Kondisi lahan yang curam menyulitkan tenaga kerja untuk memenuhi standar, semakin terampil tenaga kerja maka akan semakin mudah untuk memenuhi standar perusahaan. Kurangnya ketinggian pangkasan dapat pula dikarenakan penggunaan alat ukur yang kurang baku seperti penggunaan lutut yang menjadi ukuran setiap tanaman.

\section{Sistem Pangkasan}

Sistem pangkasan merupakan urutan pelaksanaan pemangkasan dengan jarak waktu. Sistem pangkasan yang diterapkan di UP Tambi adalah sistem pangkasan tetap. PPTK (2006) menyebutkan sistem pangkasan tetap merupakan pangkasan yang ketinggiannya relatif tetap berkisar antara $45-60 \mathrm{~cm}$. Sistem pangkasan tetap diterapkan perusahaan untuk mengantisipasi terjadinya benggul (knot) yang ada pada tanaman. Dalimoenthe dan Johan (2003) mengatakan pangkasan yang dilakukan secara berulang ulang akan menyebabkan terbentuknya bongkol bongkol seperti kaki kambing atau tanduk rusa. Bentuk percabangan (frame) yang demikian menyebabkan terhambatnya aliran hara dan air dari akar ke daun atau sebaliknya dan menghambat pertumbuhan pucuk. Apabila ditemukan adanya benggul pada tanaman, maka benggul tersebut dihilangkan atau untuk mengantisipasi agar tidak terjadinya benggul maka tanaman dipangkas beberapa $\mathrm{cm}$ diatas maupun dibawah luka lama.

\section{Gilir Pangkas}

Gilir pangkas merupakan jangka waktu antara pangkasan yang dilakukan sebelumnya dengan pangkasan yang akan dilakukan berikutnya. Puslitbangtan (2006) menyebutkan gilir pangkas adalah jangka waktu antara pemangkasan terdahulu dengan pemangkasan berikutnya dan dinyatakan dalam tahun. Penulis mendapatkan data gilir pangkas yang ada di UP Tambi dapat dilihat pada Tabel 3.

Puslitbangtan (2006) mengatakan panjang pendeknya daur pangkasan dapat dipengaruhi oleh ketinggian kebun, sistem petik, pengelolaan tanaman dan tinggi pangkasan sebelumnya. UP Tambi menggunakan gilir pangkas $4-5$ tahun karena letak perkebunan yang berada diatas 1200 mdpl. Dari hasil pengamatan dapat dilihat terdapat beberapa nomer kebun yang masih berada di luar daur pangkas. Hal ini disebabkan karena beberapa faktor dengan mempertimbangkan produksi dan kondisi tanaman yang sudah terlalu tinggi dan terlalu rapat sehingga menyulitkan dalam kegiatan pemeliharaan dan produksi. 
Tabel 3. Gilir Pangkas Beberapa Nomer Kebun di UP Tambi 2015

\begin{tabular}{|c|c|c|c|c|c|c|c|}
\hline \multirow[b]{2}{*}{ Blok } & \multirow{2}{*}{$\begin{array}{l}\text { No. } \\
\text { Kebun }\end{array}$} & \multirow[b]{2}{*}{ Luas (ha) } & \multirow{2}{*}{$\begin{array}{l}\text { Tinggi } \\
\text { tempat } \\
\text { (m dpl) }\end{array}$} & \multirow{2}{*}{$\begin{array}{c}\text { Waktu } \\
\text { pemangkasan }\end{array}$} & \multirow{2}{*}{$\begin{array}{l}\text { Pangkasan } \\
\text { berikutnya }\end{array}$} & \multicolumn{2}{|c|}{ Gilir Pangkas (bulan) } \\
\hline & & & & & & Rencana & realisasi \\
\hline \multirow{2}{*}{ Taman } & 4 & 3.89 & \multirow{2}{*}{ \pm 1300} & Feb-09 & Feb-15 & $48-60$ & $72^{*}$ \\
\hline & 11 & 4.26 & & Jan-10 & Mei-15 & $48-60$ & $64^{*}$ \\
\hline \multirow{2}{*}{ Pemangdangan } & 3 & 5.86 & \multirow{2}{*}{ \pm 1700} & Feb-10 & Jan-15 & $48-60$ & 59 \\
\hline & 5 & 3.23 & & Mei-10 & Mei-15 & $48-60$ & 60 \\
\hline \multirow{2}{*}{ Panama } & 8 & 2.95 & \multirow{2}{*}{ \pm 1400} & Mar-10 & Mar-15 & $48-60$ & 60 \\
\hline & 15 & 4.10 & & Mei-10 & Sep-15 & $48-60$ & $64^{*}$ \\
\hline \multirow{3}{*}{ Tanah Hijau } & 3 & 3.26 & \multirow{3}{*}{ \pm 1200} & Okt-09 & Jan-15 & $48-60$ & $63^{*}$ \\
\hline & 5 & 1.94 & & Jan-11 & Sep-15 & $48-60$ & 56 \\
\hline & 15 & 3.53 & & Nov-08 & Mar-15 & $48-60$ & $76^{*}$ \\
\hline
\end{tabular}

Keterangan : * menunjukan pemangkasan dilaksanakan diluar gilir pangkas

\section{Waktu Pelaksanaan Pemangkasan}

Waktu pemangkasan merupakan ketepatan waktu untuk pelaksanaan pangkasan, sehingga diperoleh hasil yang optimal. Dalam menentukan waktu pemangkasan dapat mempertimbangkan beberapa hal diantaranya kondisi tanaman, iklim, dan tinggi tempat dari permukaan laut. Pemangkasan yang dilaksanakan di UP Tambi dibagi menjadi dua semester yaitu Februari - Mei (semester 1) dan September November (semester 2). Namu kebijakan perusahaan menentukan salah satu blok yaitu blok Pemandangan untuk dilakukan satu tahap dalam pelaksanaan pemangkasan. Hal ini dikarenakan blok Pemandangan terletak pada ketinggian 1700 - $2100 \mathrm{~m} \mathrm{dpl}$, agar meminimalisir terserangnya tanaman terhadap penyakit cacar daun dan kematian tanaman. Dilihat dari segi fisiologis tanaman, waktu yang ditetapkan oleh UP Tambi dapat pula terkait dengan kadar pati yang ada pada tanaman tersebut.

\section{Luas Areal Pangkasan}

Luas areal pangkasan di UP Tambi yang direncanakan oleh kepala kebun adalah sebesar 25 $\%$ dari total luas areal tanaman menghasilkan atau sekitar 54.4 ha. Lebih lengkapnya dapat dilihat pada tabel 4.

Tabel 4. Pembagian Waktu Pelaksanaan Pemangkasan UP Tambi 2015

\begin{tabular}{|c|c|c|c|c|}
\hline \multirow{2}{*}{ Blok } & \multicolumn{2}{|c|}{ Total Pangkasan } & \multirow{2}{*}{$\begin{array}{c}\text { Luas Areal } \\
\text { Pangkasan (ha) }\end{array}$} & \multirow{2}{*}{$\begin{array}{c}\text { Luas Areal } \\
\text { Total (ha) }\end{array}$} \\
\hline & Semester 1 (ha) & Semester 2 (ha) & & \\
\hline Taman & 8.91 & 3.82 & 12.74 & 53.23 \\
\hline Pemandangan & 16.39 & 0 & 16.39 & 68.32 \\
\hline Panama & 11.57 & 4.96 & 16.54 & 60.96 \\
\hline Tanah Hijau & 6.11 & 2.61 & 8.73 & 39.38 \\
\hline Jumlah & 42.99 & 11.40 & 54.4 & 221.89 \\
\hline Persentase & $79 \%$ & $21 \%$ & $100 \%$ & $24.52 \%$ \\
\hline
\end{tabular}

Pelaksanaan pemangkasan dibagi menjadi dua semester yakni 60 - $70 \%$ pada semester I dan $30-40 \%$ pada semester II. Kebijakan yang dibuat oleh perusahaan untuk menstabilkan produksi pucuk harian agar tetap stabil. Puslitbangtan (2006) mengatakan untuk menstabilkan produksi pucuk harian agar tidak terjadi fluktuasi produksi yang terlalu besar antara saat flush dan saat minus. Sehingga pada waktu flush produksi tidak terlalu melimpah dan pada waktu kemarau tidak terlalu sedikit. Setiap blok yang ada di UP Tambi melaksanakan $2-3$ nomor kebun, kebijakan yang diberlakukan oleh kepala kebun dengan melihat jenis klon tanaman, nomor kebun yang berdekatan dan pekerjaan selesai dalam waktu yang berdekatan. Hal ini dimaksudkan agar pertumbuhan pucuk dapat serempak dan dapat dijendang secara bersamaan. 


\section{Alat Pangkas}

Alat pangkas yang digunakan di UP Tambi adalah sabit pangkas dan mesin pangkas.
Penulis mengamati perbedaan antara penggunaan alat pangkas manual maupun menggunakan mesin. Data hasil pengamatan dapat dilihat pada tabel 5.

Tabel 5. Persentase Kerusakan Cabang Berdasarkan Penggunaan Alat Pangkas di UP Tambi 2015

\begin{tabular}{|c|c|c|c|c|c|}
\hline Alat & $\sum$ Pekerja & $\begin{array}{c}\sum \text { tanaman/ } \\
\text { pekerja }\end{array}$ & $\begin{array}{c}\% \text { kerusakan cabang } \\
\emptyset<1 \mathrm{~cm}\end{array}$ & $\begin{array}{c}\% \text { kerusakan cabang } \\
\varnothing 1-1.99 \mathrm{~cm}\end{array}$ & $\begin{array}{c}\% \text { kerusakan cabang } \\
\varnothing \geq 2 \mathrm{~cm}\end{array}$ \\
\hline Mesin & 3 & 5 & $8.75 \mathrm{a}$ & $8.62 \mathrm{a}$ & $19.03 \mathrm{a}$ \\
\hline Manual & 3 & 5 & $8.91 \mathrm{~b}$ & $11.76 \mathrm{~b}$ & $16.53 \mathrm{~b}$ \\
\hline
\end{tabular}

Keterangan : angka-angka yang diikuti dengan huruf yang sama pada kolom yang sama menunjukan hasil yang berbeda nyata pada uji t-student $5 \%$.

Data hasil pengamatan menunjukan penggunaan mesin dan sabit memiliki hasil yang tidak berbeda nyata pada setiap kerusakan cabang. Namun penggunaan mesin pangkas lebih kecil persentase kerusakannya dibandingkan alat manual. Dalam hal ini penggunaan mesin dapat mengefisiensikan waktu namun para pekerja yang ada di UP Tambi kurang terampil dalam menggunakan mesin pangkas. Penggunaan sabit pangkas juga harus tajam agar dapat meminimalkan kerusakan cabang akibat luka pangkas. Apabila alat pangkas tersebut kurang tajam maka digunakan batu asah untuk mengasah sabit agar tetap tajam dan halus. Namun ketersediaan tenaga kerja tidak memungkinkan untuk dapat menggunakan mesin pangkas.
Kekurangan yang ada di lapangan adalah kurangnya alat ukur dan keterampilan tenaga kerja dalam menggunakan mesin pangkas.

\section{Tenaga Pemangkas}

Tenaga pemangkas yang ada di UP Tambi merupakan tenaga kerja musiman dengan sistem upah borongan. Sistem ini merupakan cara pembayaran apabila target pemangkasan telah selesai dan akan dibayarkan pada tanggal yang telah ditentukan. Penulis mengamati prestasi kerja yang dilaksanakan tenaga pemangkas di UP Tambi dan selengkapnya dapat dilihat pada tabel 6.

Tabel 6. Kapasitas Tenaga Pemangkas UP Tambi 2015

\begin{tabular}{|c|c|c|c|c|c|c|c|}
\hline \multirow[t]{2}{*}{ Blok } & \multirow[t]{2}{*}{ No. kebun } & \multirow[t]{2}{*}{ Luas (ha) } & \multirow{2}{*}{$\begin{array}{c}\text { Luas } \\
\text { pangkasan/hari } \\
\text { (ha) }\end{array}$} & \multicolumn{2}{|c|}{$\begin{array}{c}\text { Jumlah tenaga } \\
\text { pemangkas (hk) }\end{array}$} & \multicolumn{2}{|c|}{$\begin{array}{c}\text { Kapasitas tenaga } \\
\text { pemangkas (ha/hk) }\end{array}$} \\
\hline & & & & perhitungan & riil & perhitungan & riil \\
\hline Tanah Hijau & 15 & 3.53 & 0.13 & 3 & 2 & 0.04 & 0.07 \\
\hline Taman & 4 & 2.89 & 0.09 & 4 & 3 & 0.04 & 0.03 \\
\hline Pemandangan & 3 & 5.86 & 0.15 & 6 & 3 & 0.04 & 0.05 \\
\hline Panama & 8 & 2.95 & 0.16 & 3 & 3 & 0.04 & 0.05 \\
\hline Jumlah & & 16.23 & & 16 & 11 & & \\
\hline Rata - Rata & & & & & & 0.04 & 0.05 \\
\hline
\end{tabular}

Kapasitas pemangkasan yang ditetapkan oleh pihak kebun adalah 0.04 ha/HK. Namun pada kenyataannya setiap pekerja yang ada di UP Tambi dapat lebih cepat menyelesaikan pekerjaan dengan prestasi rata-rata 0.05 ha/HK. Dari hasil perhitungan kebutuhan tenaga pemangkas juga dapat diambil kesimpulan bahwa UP Tambi telah efektif dalam menentukan tenaga pangkas yang dipekerjakan. Dari hasil perhitungan kebutuhan tenaga pemangkas di UP Tambi adalah 16 orang, namun pada kenyataannya UP Tambi hanya memiliki 11 orang tenaga pemangkas.

\section{Pertumbuhan Tunas Setelah Pemangkasan}

Pertumbuhan tanaman teh sangat dipengaruhi oleh ketinggian tempat dari permukaan laut. Novri (2010) menyebutkan selain ketinggian, jenis klon yang ditanam juga mempengaruhi kecepatan tumbuh karena setiap klon memiliki daya adaptasi yang berbeda terhadap lingkungannya. Pengamatan dilaksanakan pada salah satu klon yang ada di UP Tambi selama 12 minggu yang tersaji pada Gambar 3. 


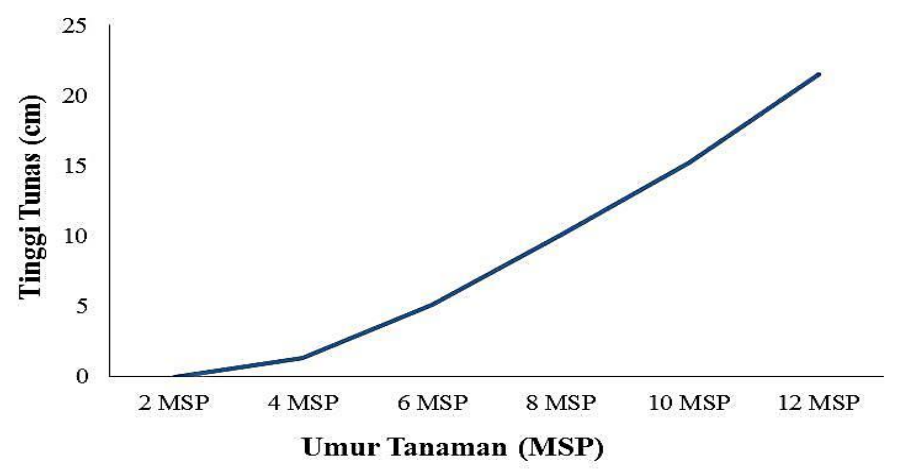

Gambar 3. Pertumbuhan Tunas Setelah Pemangkasan di UP Tambi 2015

Data diatas menunjukan pertumbuhan tunas pada salah satu blok yang berada di UP Tambi. Jenis klon yang diamati adalah Gambung 3 dan berada pada ketinggian 1300 mdpl. Pertumbuhan awal tunas terjadi pada 2 MSP dan mencapai ketinggian $21.5 \mathrm{~cm}$ pada $12 \mathrm{MSP}$. Hal ini dikarenakan pertumbuhan klon gambung 4 yang memang cocok untuk ditanam di daerah tinggi dan sedang dari permukaan laut. Selain itu klon jenis gambung juga resisten terhadap serangan cacar air. Hal ini tidak jauh berbeda dengan pengamatan yang dilakukan Novri (2010) yang mengamati klon jenis Gambung 4 namun berada pada ketinggian yang berbeda. Data Novri menunjukkan tinggi rata-rata klon gambung 4 yang berada pada ketinggian $1700 \mathrm{mdpl}$ adalah sebesar $\pm 20 \mathrm{~cm}$. Hal ini dikarenakan semakin tinggi ketinggian tempat diatas permukaan laut maka semakin lambat pertumbuhannya (Puslitbangtan 2006).

\section{KESIMPULAN}

Pelaksanaan pemangkasan di UP Tambi sangat mempertimbangkan kondisi tanaman, dana dan tenaga kerja, agar lebih efisien dalam pengeluaran dan memaksimalkan pendapatan perusahaan. Kriteria tanaman yang akan dipangkas juga telah memenuhi standar PPTK seperti, tinggi bidang petik tanaman kurang dari $120 \mathrm{~cm}$, diameter bidang petik yang lebar hingga mencapai $128.5 \mathrm{~cm}$ dan tanaman yang memiliki persentase pucuk burung yang telah melewati > $70 \%$ langsung dilaksanakan pemangkasan. Jenis pangkasan yang telah ditetapkan sudah memenuhi standar PPTK yaitu pangkasan bersih dan pengantisipasian agar tanaman tidak mati dilaksanakan pangkasan jambul. Tinggi pangkasan hampir memenuhi standar yang telah ditetapkan perusahaan yaitu $53.56 \mathrm{~cm}$ dengan sistem pangkasan tetap untuk meminimalisir terjadinya bonggol (knot) pada tanaman. Gilir pangkas yang ditetapkan adalah 4-5 tahun karena
UP Tambi termasuk perkebunan yang berada di dataran tinggi. Waktu pelaksanaan pemangkasan dibagi menjadi dua semester yaitu Februari - Mei (semester 1) dan September - November (semester 2) dengan pembagian luasan $60-70 \%$ semester 1 dan sisanya pada semester 2 . Hingga bulan Juni 2015 baru 27.99 ha atau $65 \%$ dari luasan yang akan dipangkas pada semester 1 . Penggunaan mesin pangkas sangat efisien terhadap waktu, namun pekerja yang ada kurang terampil dalam menggunakan mesin pangkas. Hal ini terlihat dari hasil pangkasan yang memiliki luka pangkas tidak halus. Jumlah tenaga pemangkas di UP Tambi telah memenuhi standar dan mempunyai kapasitas diatas standar yang telah ditetapkan oleh pabrik.

\section{DAFTAR PUSTAKA}

Pusat Penelitian Teh dan Kina [PPTK]. 2006. Petunjuk kultur teknis tanaman teh. Bandung (ID) : Lembaga Riset Perkebunan Indonesia.

Direktorat Jenderal Perkebunan. 2013. Luas areal dan produksi perkebunan seluruh Indonesia menurut pengusahaan [internet]. [diunduh 2014 Maret 8]. Tersedia pada: http://www.ditjenbun.deptan.go.id.

Direktorat Jenderal Perkebunan. 2013. Statistik perkebunan Indonesia : Teh (Camellia sinensis) 2011 - 2013. Direktorat Jenderal Perkebunan. Departemen Pertanian. Jakarta (ID) : Deptan Pr.

Johan, M.E., Dalimoenthe, S.L. 2009. Pemetikan pada Tanaman Teh. Bandung (ID) : PPTK.

Raharja, N. 2010. Pengelolaan Pemangkasan Teh (Camellia sinensis (L.) O. Kuntze) di Unit 
Perkebunan Tambi, PT Tambi, Wonosobo, Jawa Tengah. skripsi. Bogor (ID): Institut Pertanian Bogor.

Rukmana, R. 2015. Untung Selangit dari Agribisnis Teh. Yogyakarta (ID) : Lily Publisher.

Septianingrum, R L. 2013. Pemangkasan tanaman teh (Camellia sinensis (L.) O. Kuntze) di Unit Perkebunan Tambi, PT Tambi, Wonosobo, Jawa Tengah. skripsi. Bogor (ID) : Institut Pertanian Bogor.

Sukasman. 1990. Pengaruh Kandungan Pati dalam Akar Terhadap Pertumbuhan Tanaman Teh Setelah Dipangkas. Prosiding
Simposium Teh IV 1982; Semarang, Indonesia. Semarang (ID) : Balai Penelitian Teh dan Kina Gambung. 209 217 hal.

Suwarto. 2010. Budidaya Tanaman Perkebunan Unggulan. Jakarta (ID) : Penebar Swadaya.

Syah, N.A. 2006. Taklukan Penyakit dengan Teh Hijau. Jakarta (ID) : Agro Media Pustaka.

Walpole, R.E. 1992. Pengantar Statistika. Ed ke 3. Sumantri B, penerjemah. Jakarta (ID) : PT Gramedia Pustaka Utama. Terjemahan dari: Introduction to Statistics 3rd edition. $515 \mathrm{hlm}$. 